https://doi.org/10.46344/JBINO.2021.v10i2b.13

\title{
A MOLECULAR METHOD FOR DETECTING MYCOBACTERIUM TUBERCULOSIS COMPLEX IN FORMALIN-FIXED, PARAFFIN-EMBEDDED BREAST CANCER TISSUE SPECIMENS
}

\author{
Oyero S.K., ${ }^{1}$ Onwuliri F.C., ${ }^{2}$ Abdulkadir B., ${ }^{3}$ Itelima J.U., ${ }^{2}$ Dakwom Nanbam G., ${ }^{4}$ \\ Adeniyi David., ${ }^{5}$ Michael Eshioramhe Paul, ${ }^{6}$ Ebeh Emmanuel ${ }^{7}$ \\ 1Department of Histopathology, Jos University Teaching Hospital, Jos \\ 2Department of Plant Science and Biotechnology, Faculty of Natural Science, University of Jos, Jos \\ 3Department of Microbiology, Faculty of Science, Umar Musa Yar'adua University, Katsina \\ 4 North Central Tuberculosis Reference Laboratory, Jos University Teaching Hospital, Jos \\ 5 AIDS Prevention Initiative of Nigeria (APIN), Jos Area Office \\ 6 Department of Medical Microbiology Genomics Research Laboratory, University of Jos. \\ 7 AIDS Prevention Initiative of Nigeria (APIN), JUTH, Jos \\ Email : steveoyero@gmail.com,
}

\begin{abstract}
Tuberculosis (TB) of breast, caused by Mycobacterium tuberculosis, is a rare disease which often mimics carcinoma breast and is therefore often mistakenly diagnosed as such. This study was performed to investigate the usefulness of the GeneXpert (GX) molecular test in the diagnoses of TB of the breast (tuberculous mastitis) by detecting the presence of TB bacteria in breast biopsy specimens of patients diagnosed with breast carcinoma (Bca) by the histology method. The test was done on 351 formalin-fixed, paraffin embedded sections of breast tissue blocks. Mycobacterium tuberculosis complex was detected in $3(0.9 \%)$ of the 351 specimens. This study reveals that the Xpert MTB molecular test can be a useful tool in the diagnosis of extrapumonary TB in formalin-fixed, paraffin-embedded specimens.
\end{abstract}

Key Words - Xpert MTB/Rif, Breast carcinoma, Breast tuberculosis, Formalin-fixed, paraffin-embedded breast tissue, Histological diagnosis. 
INTRODUCTION

Tuberculosis (TB) constitutes a major challenge to global public health. The ability to tackle this malady has been severely hampered by inadequate diagnostic assays. Diagnosis of extrapulmonary TB (EPTB) remains especially challenging since the number of Mycobacterium tuberculosis (MTB) bacilli present in tissues at sites of disease is often low and clinical specimens from deepseated organs may be difficult to obtain (Choudhary et al., 2017). EPTB refers to TB involving organs other than the lungs, including the pleura, lymph nodes, abdomen, genitourinary tract, skin, joints and bones, meninges, among others ( $\mathrm{Ji}$, 2015). EPTB has existed for centuries and is a milder form of disease in terms of infectivity as compared to pulmonary tuberculosis (Jayshree et al., 2013). It is important that both the infectious and non-infectious forms of TB are diagnosed and treated as both can be fatal. Mammary (breast) tuberculosis is a rare manifestation of extra-pulmonary localization of the disease which accounts for less than $0.1 \%$ of breast conditions in developed countries, but reaches $3-4 \%$ in regions where the disease presents with high incidence (India, Africa). It appears mostly in women of reproductive age, multiparous, lactating as well as women of older age (Spyridon et al., 2012). It has been scarcely reported to infect male patients. For histopathological diagnosis, presence of granulomas, caseation, and demonstration of AFB have been commonly used to define a positive test. However, loss of host immune function can result in histopathologic findings demonstrating greater suppurative response and less well-formed granulomas. Additionally, the granulomas can be seen also in nontuberculous mycobacteria disease, fungal infections, brucellosis, or syphilis. So, cautious interpretation is required. Moreso, the smallness and paucity of tubercle bacilli in tissue section make it very arduous and time consuming searching for them in stained tissue sections, clinical examination often fails to differentiate carcinoma breast from tuberculosis and a high index of suspicion is necessary. Mammography is not of much help as the findings in carcinoma in advanced stage are similar to that of tubercular lesion (Jayshree et al., 2013). This study was designed to investigate the usefulness of the Xpert MTB system assay as a tool in the detection of extrapumonary $T B$ in formalin-fixed, paraffin-embedded breast cancer specimens.

\section{MATERIALS AND METHODS}

\section{Study Site}

This is a retrospective, cross-sectional, hospital based study conducted at the Jos University Teaching Hospital (JUTH); a tertiary health facility located in Jos, Plateau state, North-Central Nigeria. This area has high rates of tuberculosis.

\section{Study Population}

The study material comprised tissue specimens from women with breast cancer (Bca), collected during the period from January 2017 until December 2019. These women accessed healthcare services in tertiary hospitals in three states (Plateau, 
Nasarawa, Benue) of North Central Nigeria and were diagnosed with breast carcinoma. By random selection, 351 formalin-fixed, paraffin-embedded breast cancer tissue samples were examined.

\section{Tissue Sections Preparation}

Paraffin blocks were placed cut surface down on an ice-cold plate for at least 20 minutes. A manual rotary microtome used to obtain tissue sections was thoroughly cleaned with xylene. Cleaning was also performed before each sectioning session using xylene to remove residue paraffin wax. To minimize the potential for cross DNA contamination, gloves were worn and the microtome and surrounding station were cleaned with bleach between specimens sectioning. Also, for each block, a new microtome blade and pair of gloves were used. The block was trimmed at 15$30 \mu \mathrm{m}$. Thinner tissue sections cut at $10 \mu \mathrm{m}$ were then deparaffinized with 3 changes of pure xylene followed with descending grades of alcohol (absolute alcohol, 90\%, $70 \%, 50 \%$ alcohol) and then water for dealcoholization. These sections were then collected into sterile conical screwcapped tubes containing sterile buffered phosphate solution and taken for GeneXpert assay.

\section{Procedure for Xpert MTB/RIF Assay}

The tissue section was put into a sterile mortar using a clean, sterile pair of forceps. Approximately $2 \mathrm{ml}$ of sterile phosphate buffer solution (PBS) was added. Crushing and grinding of the tissue/PBS-solution was then done with sterile mortar and pestle until a homogeneous suspension was obtained. Approximately $0.7 \mathrm{ml}$ of homogenized tissue sample was transferred to a sterile conical, screwcapped tube using a transfer pipette. Transferring any clumps of tissue which have not been properly homogenized was avoided. A double volume of Sample Reagent $(1.4 \mathrm{ml})$ to $0.7 \mathrm{ml}$ of homogenized tissue was added using a transfer pipette. It was vortexed for at least 10 seconds. Incubated for 10 minutes at room temperature, specimen was again vortexed for at least 10 seconds. The sample was incubated at room temperature for an additional 5 minutes. Using a fresh transfer pipette, $2 \mathrm{ml}$ of the processed sample was transferred to the Xpert MTB/RIF cartridge. The cartridge was then loaded into the GeneXpert instrument as per manufacturer's instructions (Association of Public Health Laboratories, 2013).

\section{ETHICAL CONSIDERATION}

Ethical clearance was sought and obtained from the Medical Ethics and Research Committee of the hospitals concerned, before conducting the study.

\section{STATISTICAL ANALYSIS}

A descriptive statistics of frequency and percentage was used to analyze the data using SPSS statistical software (SPSS version 16. Chicago III, USA).

\section{RESULTS}

351 archived blocks of formalin-fixed, paraffin-embedded tissues from patients with diagnosis of $\mathrm{Bca}$ were examined. The sample size by year and the results 2021 April - May Special Edition | www.jbino.com | Innovative Association 
obtained are shown in Table 1. breast cancer type in which these Mycobacterium tuberculosis complex (MTBC) was detected in $3(0.9 \%)$ of the 351 organisms were detected using the Xpert MTB/Rif assay.

specimens examined. Table 2 outlines the

Table 1: Breast Cancer (Bca) Tissues screened using the Xpert MTB/Rif Test

\begin{tabular}{lccc}
\hline Year & $\begin{array}{c}\text { Sample } \\
\text { Size }\end{array}$ & $\begin{array}{c}\text { MTBC* } \\
\text { Detected }\end{array}$ & $\begin{array}{c}\text { Percentage } \\
\text { MTBC detected }\end{array}$ \\
\hline 2017 & 87 & 0 & 0.00 \\
2018 & 115 & 2 & 0.60 \\
2019 & 149 & 1 & 0.30 \\
TOTAL & 351 & 3 & 0.90 \\
\hline
\end{tabular}

*MTBC $=$ Mycobacterium tuberculosis complex

Table 2: Breast tuberculosis in relation to Breast cancer (Bca)

Types, detected by the Xpert MTB/Rif Assay

\begin{tabular}{llllll}
\hline Bca Type & 2017 & 2018 & 2019 & TOTAL & $*$ MTBC (\%) \\
\hline Invasive Ductal Ca & 54 & 69 & 87 & 208 & $3(0.90)$ \\
Invasive Mucinous Ca & 12 & 18 & 27 & 57 & $0(0.00)$ \\
Invasive Lobular Ca & 7 & 10 & 14 & 31 & $0(0.00)$ \\
Invasive Papillary Ca & 3 & 6 & 8 & 17 & $0(0.00)$ \\
Metaplastic carcinoma & 3 & 3 & 4 & 10 & $0(0.00)$ \\
Others & 8 & 9 & 11 & 28 & $0(0.00)$ \\
TOTAL & 87 & 113 & 151 & 351 & $3(0.90)$ \\
\hline
\end{tabular}

*MTBC = Mycobacterium tuberculosis complex 


\section{DISCUSSION}

Sustainable global tuberculosis control cannot be achieved using the current conventional diagnostic tools and strategies which are grossly inadequate to easily capture all latent and active TB cases and obviate the raging spread of the disease. These challenges are particularly acute in Sub-Saharan Africa which endures the highest burden of active TB, where in both the community and hospital settings, many cases of active TB and drug-resistant TB remain undiagnosed (Bate et al., 2012; Lawn et al., 2015). Presently, researchers have started experimenting with the use of the Xpert MTB/RIF assay for detecting M. tuberculosis in nonrespiratory specimens and several studies have assessed the utility of the Xpert MTB/RIF assay for the diagnosis of EPTB through analysis of biopsy specimens, including various body fluids or fresh and frozen tissues. When compared with MTB culture as the gold standard, the Xpert MTB/RIF assay has a generally high specificity in a range of specimen types, but studies report very varied sensitivity results, with pooled values as low as $34 \%$ (95\% confidence interval [Cl]: $24 \%-44 \%$ ) in pleural fluid, but as high as $96 \% 195 \% \mathrm{Cl}$ : 72\%-99\%) in lymph nodes (Maynard-Smith et al., 2014; Polepole et al., 2017). This novel, automated, cartridge-based nucleic acid amplification test (NAAT) is considered useful for rapid molecular diagnosis of EPTB (Bowles et al., 2011). A recent meta-analysis reported that Xpert MTB/RIF has an overall sensitivity of $83.1 \%$ and a pooled specificity of $98.7 \%$ for the diagnosis of EPTB (Somoskovi et al., 2013).
Although there have not appeared to be any causal link between breast tuberculosis and breast carcinoma, and there is no recorded evidence that tuberculosis is carcinogenic at any site (Bani-Hani, 2005), in this study 351 FFPE breast cancer tissue specimens were screened for MTBC using the Xpert MTB/RIF molecular test. This research was conceived in view of the fact that breast cancer on one hand and tuberculosis on the other, are burdensome diseases among women, in the study locations. MTBC was detected in $3(0.9 \%)$ of the 351 specimens examined. The patients had no record/history or symptoms of TB. There may have been a missed diagnosis in the histopathology investigation.

Most studies to date have used fresh or fresh-frozen tissue or biopsy specimens for Xpert analysis, but the routine method for handling biopsy or postmortem tissue in a diagnostic histopathology laboratory is to fix the specimen with formalin and embed it in paraffin wax. Whether fresh from the tissue processor or from archived biobanks, formalin-fixed paraffin-embedded (FFPE) tissues are important diagnostic research materials as they are noninfectious, have a better preserved cellular architecture, and hence are suitable for morphological evaluation and can be kept for a long time, making them useful for retrospective studies. In this research, the molecular detection of Mycobacterium tuberculosis was done on formalin-fixed, paraffinembedded tissue specimens.

\section{April - May Special Edition | www.jbino.com | Innovative Association}




\section{CONCLUSION}

The coexistences of breast carcinoma and tuberculosis mastitis are very rare. Where it occurs, it could create a dilemma in the diagnosis and treatment, as there are often no pathognomonic features to differefulentiate malignancy from breast tuberculosis. This research finding suggests that the use of molecular methods such as the Xpert MTB/RIF assay on FFPE tissue may be a reliable, effective tool for detecting extrapulmonary tuberculosis.

\section{REFERENCES}

Association of Public Health Laboratories (2013). Laboratory Considerations for Use of Cepheid Xpert MTB/RIF Assay. CepheidXpert-Fact-Sheet, Pp. 28-56.

Bani-Hani K.E., Yaghan, R.J., Matalka, I.I. \& Mazahreh, T.S. (2005). Tuberculous mastitis: a disease not to be forgotten.

International Journal of Tuberculosis and Lung Diseases, 9(8): 920 -50.

Bates, M., O'Grady, J., Mwaba, P., Chilukutu, L., Mzyece, J. \& Cheelo, B. (2012). Evaluation of the burden of unsuspected pulmonary tuberculosis and co-morbidity with non-communicable diseases in sputum producing adult inpatients. PLoS One (7): e40774

Bowles, E.C., Freyee, B., Van Ingen, J., Mulder, B., Boeree, M.J. \& Van Soolingen D (2011). Xpert MTB/RIF, novel automated polymerase chain reactionbased tool for the diagnosis of tuberculosis. Int J Tuberc Lung Dis. 2011;15: 988-989.

Choudhary, V., Pankaj, S., Harsvardhan., R. (2017). Tuberculosis of Breast Mimicking Breast Carcinoma: A Case Report and
Review of Literature. Indian Journal of Gynecological Oncology, 15, 5.

Deggim, V., Somoskovi, A., Voit, A., Böttger, E.C. \& Bloemberg, G. V. (2013). Integrating the Xpert MTB/RIF assay into a diagnostic workflow for rapid detection of Mycobacterium tuberculosis in a lowprevalence area. Journal of Clinical Microbiology (51): 2396-2399.

Jayshree, D.P., Sanjay, D.R., Parimal, H. P., Parul, D. S., Lata, R. P. \& Jignesh, A. P. (2013). Screening of extrapulmonary tuberculosis samples by zeihl neelsen staining in patients presenting at tertiary care hospital Ahmedabad. National Journal of Community Medicine, 4:1 1

Ji Y. L. (2015). Diagnosis and Treatment of Extrapulmonary Tuberculosis. Tuberculosis of Respiratory Diseases (Seoul), 78(2): 47-55.

Lawn, S.D., Kerkhoff, A.D., Burton, R., Schutz, C., van Wyk, G. \& Vogt M., et al. (2015). Rapid microbiological

screening for tuberculosis in HIV-positive patients on the first day of acute hospital admission by systematic testing of urine samples using Xpert MTB/RIF: A prospective cohort in South Africa. BMC Med (13): 192.

Maynard-Smith, L., Larke, N., Peters, J.A.\& Lawn, S.D. (2014). Diagnostic accuracy of the Xpert MTB/RIF assay extrapulmonary and pulmonary tuberculosis when testing non-respiratory samples: A systematic review. BMC Infectious Disease, 14:709.

Polepole, P., Kabwe, M., Kasonde, M., Tembo, J., Shibemba, A., O'Grady, J., Kapata, N., Zumla, A. \& Bates, M.

(2017).Performance of the Xpert MTB/RIF assay in the diagnosis of tuberculosis in 2021 April - May Special Edition | www.jbino.com | Innovative Association 
formalin-fixed, paraffin-embedded tissues. International Journal of Mycobacteriology, 29(6):87-93

Somoskovi, A., Voit, A., Böttger, E.C. \& Bloemberg, G.V. (2013). Integrating the Xpert MTB/RIF assay into a diagnostic workflow for rapid detection of Mycobacterium tuberculosis in a low- prevalence area. Journal of Clinical Microbiology, 51: 2396-2399

Spyridon, M., Dionysia L., Thomas G., Constantine D., Irini P. \& Aris A. (2012). Breast tuberculosis: Diagnosis, management and treatment. International Journal of Surgical Case Reports, 3(11): $548-550$. 